\title{
Treatment of Chronic Oxaliplatin-Induced Peripheral Neuropathy: A Systematic Review
}

\author{
Alda Tavares $^{1^{*}}{ }^{\infty}$, Ana Agrelo $^{2}$, Manuela Machado $^{3}$ \\ ${ }^{1}$ Department of Medical Oncology, Hospital Pedro Hispano, Matosinhos Local Health Unit, Matosinhos, Portugal \\ ${ }^{2}$ Department of Anesthesiology, Portuguese Institute of Oncology of Porto, Porto, Portugal \\ ${ }^{3}$ Department of Medical Oncology, Portuguese Institute of Oncology of Porto, Porto, Portugal \\ Email: *alda.tavares@ulsm.min-saude.pt
}

How to cite this paper: Tavares, A., Agrelo, A. and Machado, M. (2020) Treatment of Chronic Oxaliplatin-Induced Peripheral Neuropathy: A Systematic Review. Journal of Cancer Therapy, 11, 519-534. https://doi.org/10.4236/jct.2020.119045

Received: June 27, 2020

Accepted: September 13, 2020

Published: September 16, 2020

Copyright $\odot 2020$ by author(s) and Scientific Research Publishing Inc. This work is licensed under the Creative Commons Attribution International License (CC BY 4.0).

http://creativecommons.org/licenses/by/4.0/

\begin{abstract}
Introduction: Oxaliplatin is a platinum-derivative chemotherapeutic agent used in digestive tumours, in the adjuvant and metastatic setting. Oxaliplatin can cause a chronic peripheral sensory neuropathy which impacts the quality of life and is dose limiting. To date, no therapeutic strategies have proved effective in the treatment of oxaliplatin-induced peripheral neuropathy (OIPN). Methods: A computerized search of the literature on PubMed database was performed. Publisher original articles were included if they focused on treatment of peripheral neuropathy among patients submitted to oxaliplatin. Eleven out of 242 reviewed papers met our inclusion criteria and were subjected to a 19-item quality checklist. Results: The included studies differed with respect to study design, patient population and sample size, neuropathic symptoms assessment and efficacy measure. Most studies had an adequate quality. Ten trials tested one drug, and one pilot study tested a non-pharmacological treatment-the neurofeedback. Of these, 3 trials included only patients submitted to oxaliplatin-based chemotherapy. Duloxetine showed moderate efficacy in 3 trials. Topical treatment with capsaicin or 10\% amitriptyline was promisors in 2 single-arm trials with a few samples. Conclusion: In the last decade, there wasn't an improvement in the treatment of chronic OIPN. The duloxetine is the unique drug with moderate efficacy on the treatment of OIPN. There is insufficient evidence to support a recommendation for any other treatment.
\end{abstract}

\section{Keywords}

Peripheral Neuropathy, Oxaliplatin, Chemotherapy-Induced Peripheral Neuropathy, Pain, Neurotoxicity, Supportive Care 


\section{Introduction}

Oxaliplatin is a platinum-derivative chemotherapeutic agent used in digestive tumours, in the adjuvant and metastatic setting [1] [2] [3]. Neurotoxicity is the most significant adverse effect. Oxaliplatin-induced peripheral neuropathy (OIPN) occurs in two distinct forms: an acute neurotoxicity and a chronic cumulative sensory neuropathy [3] [4] [5] [6]. Acute symptoms manifest as a cold-precipitated tingling distal paraesthesia and pain, perioral paresthesias and muscle cramps, in approximately $80 \%$ of patients. These symptoms occur within hours or days after oxaliplatin course and typically resolve within a week of infusion [7]. It does not require dose reduction.

The chronic form of OIPN is a pure sensory, axonal neuropathy and is usually seen after cumulative doses of $780-850 \mathrm{mg} / \mathrm{m}^{2}$. It can surge after discontinuation treatment [8]. OIPN may be present in $26 \%-46 \%$ of patients at the 12 -month follow-up [8]. Typical presentation is characterized of devastating and non-cold related pain and pronounced dysesthesia/paraesthesia, according to a typically, symmetrical and distal, "stocking and glove" distribution. Sensory loss and dysfunction of fine sensory-motor coordination can also occur. Motor nerve function usually remains normal. OIPN improves, not completely, in approximately 6 - 8 months after discontinuation of oxaliplatin treatment, especially in upper extremities [2] [3] [7]. OIPN leads to a reduction in dose(s) and/or discontinuation of chemotherapy (ChT), which can negatively impact cancer-related outcomes. Chronic OIPN contributes for functional difficulties with activities of daily living and a negative influence on quality of life [7] [9]. It is an important concern for long-term survivors. Beyond the established association with oxaliplatin dose, no clinical or patient-related factors were consistently associated with the incidence and severity of OIPN [10]. To date, no prevention strategies of OIPN have proved effective [2] [3] [11] [12].

Face to other neurotoxic ChT regimens (taxanes, vinca alkaloids, etc.), oxaliplatin caused a unique spectrum of clinical presentation [13] [14]. Studies suggested that OIPN occurred by a different mechanism compared to other neurotoxic agents, not yet fully understood [14] [15]. Treatment of chemotherapy-induced peripheral neuropathy (CIPN) with different drugs, with different mechanisms of action, was disappointed until now [16]. So, management of chronic OIPN is a substantial challenge for medical oncologists.

To address this issue, in this systematic review, we aimed to identify all studies, irrespective of study design, that investigated pharmacological and non-pharmacological treatments for chronic OIPN.

\section{Material and Methods}

Preferred Reporting Items for Systematic Reviews and Meta-Analysis (PRISMA) statement [17] was used as a guide and template for every step of the study.

An electronic search of the PubMed database was performed to obtain key literature in the field of OIPN. Final access dates February 2, 2020. The medical 
subject heading $(\mathrm{MeSH})$ search included: (peripheral neuropathy [MeSH Terms] OR peripheral neurotoxicity [MeSH Terms]), AND oxaliplatin [MeSH Terms], AND (treatment [MeSH Terms] OR management [MeSH Terms]). Only one selection filter was used, which was a "clinical trial".

Studies that met the following criteria were included: 1) if CIPN was assessed among cancer patients treated with oxaliplatin; 2) if the study focus is the treatment of CIPN; 3) if the publication was an original study (e.g. no review, poster abstracts, editorials, letters to the editor, etc.); 4) if they were published in peer-reviewed journals and, 5) if they were written in English. Studies were included irrespective of study design, cancer diagnosis or year of publication. Additional studies were included after analysed of the references of the selected full texts, based on the same inclusion criteria. In summary, therapeutic phase II or III clinical trials investigating the efficacy of pharmacological or non-pharmacological treatment of CIPN, among patients treated with oxaliplatin, published in English, were considered for this review.

Table 1 illustrates the detailed criteria for quality assessment of the eligible studies was conducted, which they based on criteria adapted from a previously published systematic review on OIPN [10] and the CONSORT statement checklist [18].

Detailed data from study design, type of study (single, multicentric, or population-based cohort), characteristics of the patient population (cancer diagnosis, the regimen of chemotherapy and other), treatment (pharmacological or non-pharmacological management), and treatment outcomes, were extracted from the eligible studies and resumed in Table 2.

\section{Results}

Figure 1 summarizes the study selection process in a stepwise fashion with reasons for exclusion at each step. Overall, a total of 242 papers were retrieved. A preliminary review of the title and abstracts led to exclusion of 233 papers for 3 reasons: studies do not focus on OIPN; studies focus on prevention of OIPN and studies focus on other themes like pathophysiology, OIPN assessment methods, etc. For the remaining 9 articles were reviewed to determine eligibility. Two relevant non-English studies were excluded. One article was eliminated due to address not-human participants. After reviewing the reference text of the remaining 6 articles [19]-[24], 5 additional relevant articles were included [25] [26] [27] [28] [29].

Table 2 illustrates a summary of the key characteristics of the reviewed trials as well as their studied population, intervention and important outcomes.

A total of 11 articles were included in the review, all of which were published between 2007 and 2019. Ten trials tested pharmacological treatment of CIPN, of these 6 used oral drugs: duloxetine, amitriptyline, gabapentin and pregabalin; and 4 trials used topical treatment (capsaicin and amitriptyline-based formulations). The only trial based on non-pharmacological intervention applied the neurofeedback strategy [22]. 
Table 1. List of criteria for assessing the methodological quality of studies on the treatment of OIPN. The right column indicates the number of publications, out of the total 11 reviewed here, that met the respective criteria.

\begin{tabular}{lc}
\multicolumn{1}{c}{ Evaluation criteria } & $\mathrm{N}=11$ \\
\hline Study design & $9(82 \%)$ \\
1) Description of the setting (dates, period of enrolment) & $11(100 \%)$ \\
2) Inclusion and exclusion criteria were described & $7(64 \%)$ \\
3) Justification explained for the selected study population size & $11(100 \%)$ \\
4) Details of the interventions (pharmacological or non-pharmacological \\
treatment), to allow replication
\end{tabular}

\section{Neuropathy-related}

9) Neuropathy assessment criteria described (NCI-CTCAE criteria or neuropathy questionnaire)

10) A neuropathy exam was performed

11) Neurophysiological testing was performed

12) Chronic CIPN was defined or implied

\section{Study population}

13) The clinical variables "age", "sex" and "cancer disease" was described

14) Inclusion of patients undergoing exclusively to oxaliplatin-based ChT

\section{Results}

16) Number of patients reported at each group or subgroup (eligible, included, analysed)

18) Description objectively response in CIPN relief

19) Addressed limitations and potential sources of bias

$7(64 \%)$

Legends: NCCI-CTCAE: National Cancer Institute's Common Toxicity Criteria for Adverse Events; CIPN Chemotherapy-induced peripheral neuropathy; ChT: chemotherapy. 
Table 2. Clinical trials on the treatment of chronic OIPN: study characteristics and main outcomes. The rights columns indicate the evaluation criteria presented in each study and a total of points for assessing the methodological quality of respective publications.

\begin{tabular}{|c|c|c|c|c|c|c|c|c|c|c|}
\hline $\begin{array}{l}\text { Reference } \\
\text { (year, } \\
\text { country) }\end{array}$ & $\begin{array}{l}\text { Study } \\
\text { Design }\end{array}$ & $\mathrm{N}$ & Treatment & $\begin{array}{c}\text { CIPN } \\
\text { assessment }\end{array}$ & $\begin{array}{l}\text { Cancer and } \\
\text { ChT regimen }\end{array}$ & $\begin{array}{l}\text { Primary } \\
\text { Efficacy } \\
\text { Measures }\end{array}$ & $\begin{array}{c}\text { Outcomes } \\
\text { (effectiveness) }\end{array}$ & $\begin{array}{l}\text { Side effects and } \\
\text { interactions }\end{array}$ & $\begin{array}{l}\text { Study } \\
\text { quality }\end{array}$ & $\begin{array}{l}\text { Quality } \\
\text { criteria } \\
\text { items }\end{array}$ \\
\hline $\begin{array}{c}\text { Yang Y. } \\
(2012 \text {, } \\
\text { China) } \\
\text { [19] }\end{array}$ & $\begin{array}{l}\text { Unicentric trial, } \\
\text { single-arm. }\end{array}$ & 39 & $\begin{array}{l}\text { Duloxetine } \\
60 \mathrm{mg} / \text { day } \\
(30 \mathrm{mg} / \text { day in } \\
\text { first week, and } \\
60 \mathrm{mg} / \text { day in } \\
\text { subsequent } \\
11 \text { weeks) }\end{array}$ & $\begin{array}{l}\text { Symptomatic } \\
\text { CIPN, with } \\
\text { NCI-CTCAE } \\
\text { v3.0 grade } \\
1-3\end{array}$ & $\begin{array}{l}\text { Colon cancer, } \\
\text { in stage III or } \\
\text { IV, submit to } \\
\text { oxaliplatin-based } \\
\text { ChT }\end{array}$ & $\begin{array}{c}\text { VAS and } \\
\text { NCI-CTCAE } \\
\text { v3.0, on } \\
\text { baseline and } \\
\text { at } 12 \text { weeks }\end{array}$ & $\begin{array}{l}>30 \% \text { VAS } \\
\text { score reduction } \\
\text { in } 63,3 \% \text { and } \\
\text { NCI-CTCAE } \\
\text { v3.0 grade } \\
\text { improvement } \\
\text { in } 47.4 \% \text { of pts }\end{array}$ & $\begin{array}{c}\text { Discontinuation } \\
\text { in } 23 \% \text { by } \\
\text { adverse effects } \\
\text { (dizziness/nausea: } \\
10 \% \text {, somnolence: } \\
5 \% \text {, insomnia: } \\
5 \% \text { ) }\end{array}$ & 13 & $\begin{array}{c}1,2,4,5 \\
6,9,13 \\
14,15 \\
16,17 \\
18,19\end{array}$ \\
\hline $\begin{array}{c}\text { Smith E. } \\
(2013, \text { USA) } \\
{[20]}\end{array}$ & $\begin{array}{l}\text { Multicentric, } \\
\text { phase III } \\
\text { randomized, } \\
\text { double-blind, } \\
\text { placebo-controlled, } \\
\text { crossover trial }\end{array}$ & 231 & $\begin{array}{l}\text { Duloxetine } \\
60 \mathrm{mg} / \text { day } \\
(30 \mathrm{mg} / \text { day in } \\
1^{\text {st }} \text { week, and } \\
60 \mathrm{mg} / \text { day in } \\
\text { subsequent } \\
4 \text { weeks })\end{array}$ & $\begin{array}{c}\text { CIPN with } \\
\text { NCI-CTCAE } \\
\text { v3.0 grade } \geq 1 \text {; } \\
\text { and an average } \\
\text { pain score } \geq 4 \text {, } \\
\text { for } \geq 3 \text { months } \\
\text { beyond ChT } \\
\text { completion }\end{array}$ & $\begin{array}{c}\text { Any cancer } \\
\text { and stage. Pts } \\
\text { submitted to ChT } \\
\text { with paclitaxel, } \\
\text { oxaliplatin, } \\
\text { docetaxel, } \\
\text { nab-paclitaxel, } \\
\text { or cisplatin. }\end{array}$ & $\begin{array}{l}\text { BPI-SF } \\
\text { "average pain" } \\
\text { (based to } \\
\text { NRS), weekly }\end{array}$ & $\begin{array}{l}\text { Any decrease } \\
\text { pain in } 59 \% \text { of } \\
\text { pts treated with } \\
\text { duloxetine vs. } \\
38 \% \text { of pts on } \\
\text { placebo arm, } \\
\text { with a mean } \\
\text { decrease in } \\
\text { average pain of } \\
1.06 \text { and } 0.34, \\
\text { respectively }\end{array}$ & $\begin{array}{c}\text { Duloxetine } \\
\text { discontinuation } \\
\text { in } 11 \% \text { by } \\
\text { adverse effects } \\
\text { (fatigue: } 7 \% \text {, } \\
\text { insomnia: } 5 \% \text {, } \\
\text { nausea: } 5 \% \text { ) }\end{array}$ & 16 & $\begin{array}{c}1,2,3,4 \\
5,6,7,8 \\
9,10,12 \\
13,16 \\
17,18,19\end{array}$ \\
\hline $\begin{array}{l}\text { Hirayama } \\
\text { Y. (2015, } \\
\text { Japan) } \\
{[21]}\end{array}$ & $\begin{array}{l}\text { Unicentric, phase II } \\
\text { randomized, } \\
\text { open-label, crossover } \\
\text { trial (duloxetine vs. } \\
\text { vitamin B12) }\end{array}$ & 34 & $\begin{array}{l}\text { Duloxetine } \\
40 \mathrm{mg} / \text { day } \\
\text { (20 mg/day in } \\
\text { first week, and } \\
40 \mathrm{mg} / \text { day in } \\
\text { subsequent } \\
3 \text { weeks) }\end{array}$ & $\begin{array}{l}\text { Descriptors of } \\
\text { neuropathic } \\
\text { numbness } \\
\text { or pain }\end{array}$ & $\begin{array}{l}\text { Any cancer } \\
\text { and stage. } \\
\text { Pts submitted } \\
\text { to ChT with } \\
\text { paclitaxel, } \\
\text { oxaliplatin, } \\
\text { vincristine, or } \\
\text { bortezomib. }\end{array}$ & $\begin{array}{c}\text { VAS, on } \\
\text { baseline and } \\
\text { weekly }\end{array}$ & $\begin{array}{l}>30 \% \text { VAS score } \\
\text { reduction in } \\
\text { numbness and } \\
\text { pain in } 80 \% \text { and } \\
73 \% \text { of pts, } \\
\text { respectively } \\
\text { (compared to } 24 \\
\text { and } 18 \% \text { related } \\
\text { to vitamin } \mathrm{B} 12 \text { ) }\end{array}$ & $\begin{array}{l}\text { Duloxetine } \\
\text { discontinuation } \\
\text { in } 15 \% \text { by } \\
\text { adverse effects } \\
\text { (fatigue: } 18 \% \text { ) }\end{array}$ & 11 & $\begin{array}{c}1,2,3,4 \\
5,6,7 \\
13,16 \\
17,18\end{array}$ \\
\hline $\begin{array}{l}\text { Kautio } \\
\text { A. L. }(2008 \text {, } \\
\text { Finland) } \\
{[29]}\end{array}$ & $\begin{array}{l}\text { Unicentric, } \\
\text { randomized, } \\
\text { double-blind, } \\
\text { placebo-controlled trial }\end{array}$ & 44 & $\begin{array}{c}\text { Amitriptyline } \\
(10-50 \mathrm{mg} / \text { day }) \\
\text { for } 8 \text { weeks }\end{array}$ & $\begin{array}{l}\text { Severity of } \\
\text { CIPN (pain, } \\
\text { numbness, } \\
\text { and tingling) } \\
\geq 3 \text { out of } 10\end{array}$ & $\begin{array}{c}\text { Any cancer } \\
\text { and stage. } \\
\text { Pts treated with } \\
\text { neurotoxic ChT } \\
\text { during } \geq 2 \\
\text { months }\end{array}$ & $\begin{array}{l}\text { Neuropathic } \\
\text { symptoms, } \\
\text { assessed by } \\
\text { numeric } \\
\text { scales }(0-10) \text {, } \\
\text { twice a week }\end{array}$ & $\begin{array}{c}\text { Nonsignificant } \\
\text { trend toward } \\
\text { better global } \\
\text { improvement } \\
\text { with } \\
\text { amitriptyline }\end{array}$ & $\begin{array}{l}15 \text { of the } 17 \mathrm{pts} \\
\text { were on the } \\
\text { target dose } \\
\text { (50 mg/day). }\end{array}$ & 10 & $\begin{array}{c}1,2,4,5 \\
6,7,9 \\
13,16,19\end{array}$ \\
\hline $\begin{array}{c}\text { Rao R. } \\
(2007, \text { USA }) \\
{[25]}\end{array}$ & $\begin{array}{l}\text { Multicentric, phase } \\
\text { III randomized, } \\
\text { double-blind, } \\
\text { placebo-controlled, } \\
\text { crossover trial }\end{array}$ & 115 & $\begin{array}{l}\text { Gabapentin } \\
(300 \mathrm{mg} / \text { day } \\
\text { with dose } \\
\text { incremented in } \\
3 \text { weeks, up to } \\
2700 \mathrm{mg} / \text { day) } \\
\text { for } 6 \text { weeks }\end{array}$ & $\begin{array}{l}>1 \text { month } \\
\text { symptomatic } \\
\text { CIPN, with } \\
\text { pain } \mathrm{NRS} \geq 4 \\
\text { or ENS } \geq 1\end{array}$ & $\begin{array}{c}\text { Any cancer } \\
\text { and stage. Active } \\
\text { or previous } \\
\text { treatment with } \\
\text { neurotoxic ChT }\end{array}$ & $\begin{array}{l}\text { NRS and } \\
\text { ENS } \\
\text { (weekly) }\end{array}$ & $\begin{array}{l}\text { No significant } \\
\text { differences in } \\
\text { primary } \\
\text { endpoints }\end{array}$ & $\begin{array}{l}\text { Adverse events } \\
\text { occurred at } \\
\text { relatively } \\
\text { equivalent rates } \\
\text { in both groups. }\end{array}$ & 13 & $\begin{array}{c}1,2,3,4 \\
5,6,7,8 \\
9,12,16 \\
18,19\end{array}$ \\
\hline $\begin{array}{c}\text { Saif M. } \\
(2010, \text { USA) } \\
{[26]}\end{array}$ & $\begin{array}{l}\text { Unicentric trial, } \\
\text { single-arm }\end{array}$ & 23 & $\begin{array}{l}\text { Pregabalin } \\
50 \mathrm{mg} \mathrm{tid} \rightarrow \\
150 \mathrm{mg} \text { tid }\end{array}$ & $\begin{array}{l}\text { CIPN with } \\
\text { NCI-CTCAE } \\
\text { v3.0 grade } \\
2-3\end{array}$ & $\begin{array}{l}\text { Gastrointestinal } \\
\text { cancer pts } \\
\text { treated with } \\
\text { oxaliplatin-based } \\
\text { ChT }\end{array}$ & $\begin{array}{l}\text { NCI-CTCAE } \\
\text { v3.0, every } 2 \\
\text { weeks }\end{array}$ & $\begin{array}{l}\text { NCI-CTCAE } \\
\text { v3.0 grade } \\
\text { improvement } \\
\text { in } 48 \% \text { of pts }\end{array}$ & $\begin{array}{c}\text { Discontinuation } \\
\text { in } 3 \text { pts. The } 3 \\
\text { more frequent } \\
\text { side effects are: } \\
\text { dizziness ( } 57 \%) \text {, } \\
\text { headache }(26 \%) \text {, } \\
\text { somnolence } \\
(22 \%) .\end{array}$ & 11 & $\begin{array}{c}1,2,4,5 \\
6,9,13 \\
14,16 \\
17,18\end{array}$ \\
\hline
\end{tabular}




\section{Continued}

\begin{tabular}{|c|c|c|c|c|c|c|c|c|c|c|}
\hline $\begin{array}{l}\text { Filipczak- } \\
\text { Bryniarska } \\
\text { I. (2017, } \\
\text { Poland) } \\
\text { [23] }\end{array}$ & $\begin{array}{l}\text { Unicentric trial, } \\
\text { single-arm }\end{array}$ & 18 & $\begin{array}{l}\text { High-dose } 8 \% \\
\text { Capsaicin } \\
\text { patch }\end{array}$ & $\begin{array}{c}\text { Painful } \\
\text { peripheral } \\
\text { polyneuropathy } \\
\text { (clinical history } \\
\text { and neurological } \\
\text { examination by } \\
\text { a neurologist), } \\
\text { with NRS } \geq 4\end{array}$ & $\begin{array}{l}\text { Colon cancer, } \\
\text { submit to } \\
\text { oxaliplatin-based } \\
\text { ChT }\end{array}$ & $\begin{array}{c}\text { NRS at } \\
\text { baseline and } \\
\text { on } 1 \text { and } 8 \\
\text { days after, } \\
\text { and } 8 \text { and } 12 \\
\text { weeks after }\end{array}$ & $\begin{array}{l}\text { Reduction of } \\
\text { NRS score } \\
\text { occurred in } \\
84 \%-97 \% \\
\text { of pts, after } \\
12 \text { weeks. }\end{array}$ & $\begin{array}{l}\text { None of the } \\
\text { adverse events } \\
\text { occurred. }\end{array}$ & 13 & $\begin{array}{c}1,2,4,5 \\
6,9,10 \\
13,14 \\
16,17 \\
18,19\end{array}$ \\
\hline $\begin{array}{c}\text { Barton D. L. } \\
\text { (2011, USA) } \\
{[27]}\end{array}$ & $\begin{array}{l}\text { Multicentric, } \\
\text { randomized, } \\
\text { double-blind, } \\
\text { placebo-controlled trial }\end{array}$ & 208 & $\begin{array}{l}\text { Topical BAK gel } \\
\text { (baclofen } 0.8 \% \text {, } \\
\text { amitriptyline } 3 \% \\
\text { and ketamine } \\
1.5 \% \text { ), bid, } \\
\text { for } 4 \text { weeks }\end{array}$ & $\begin{array}{l}>1 \text { month } \\
\text { symptomatic } \\
\text { CIPN, with } \\
\text { numbness, } \\
\text { tingling or pain } \\
\text { level of } \geq 4 \\
\text { out of } 10\end{array}$ & $\begin{array}{c}\text { Any cancer } \\
\text { and stage. Active } \\
\text { or previous } \\
\text { treatment with } \\
\text { neurotoxic } \\
\text { ChT }\end{array}$ & $\begin{array}{c}\text { Sensory } \\
\text { subscale of } \\
\text { the EORTC } \\
\text { QLQ-CIPN20, } \\
\text { at baseline } \\
\text { and } 4 \text { weeks } \\
\text { after }\end{array}$ & $\begin{array}{c}\text { A greater } \\
\text { improvement } \\
\text { for BAK arm } \\
\text { (vs. placebo) } \\
\text { in the sensory } \\
\text { subscale } \\
(p=0.053) .\end{array}$ & $\begin{array}{l}\text { Without } \\
\text { undesirable } \\
\text { toxicities. } \\
\text { No evidence } \\
\text { of systemic } \\
\text { toxicity. }\end{array}$ & 12 & $\begin{array}{c}1,2,3,4 \\
5,6,7,8 \\
9,12,16 \\
19\end{array}$ \\
\hline $\begin{array}{l}\text { Gewandter J. } \\
\text { S. (2014, } \\
\text { USA) } \\
{[28]}\end{array}$ & $\begin{array}{l}\text { Multicentric, phase } \\
\text { III randomized, } \\
\text { double-blind, } \\
\text { placebo-controlledtrial }\end{array}$ & 462 & $\begin{array}{c}\text { Topical } \\
\text { KA cream } \\
\text { (ketamine } 2 \% \\
\text { and amitriptyline } \\
4 \% \text { ), bid, for } \\
6 \text { weeks }\end{array}$ & $\begin{array}{l}\text { CIPN (pain, } \\
\text { numbness, and } \\
\text { tingling) } \geq 4 \\
\text { out of } 10 ; \\
\geq 1 \text { month } \\
\text { beyond ChT } \\
\text { completion }\end{array}$ & $\begin{array}{l}\text { Any cancer } \\
\text { and stage. } \\
\text { Previous } \\
\text { treatment with } \\
\text { neurotoxic } \\
\text { ChT (taxane } \\
\text { vs. non-taxane) }\end{array}$ & $\begin{array}{c}\text { Pain, } \\
\text { numbness, } \\
\text { and tingling } \\
\text { scoresat } \\
\text { baseline and } \\
\text { at } 6 \text { weeks } \\
\text { after }\end{array}$ & $\begin{array}{l}\text { No effect on } \\
\text { 6-week CIPN } \\
\text { scores } \\
(p=0.363) .\end{array}$ & $\begin{array}{l}\text { Adverse events } \\
\text { occurred at } \\
\text { relatively } \\
\text { equivalent rates } \\
\text { and severity } \\
\text { in both arms. }\end{array}$ & 11 & $\begin{array}{l}2,3,4,5, \\
6,7,8,9, \\
13,16,18\end{array}$ \\
\hline $\begin{array}{l}\text { Rossignol } \\
\text { J. (2019, } \\
\text { France) } \\
\quad[24]\end{array}$ & $\begin{array}{c}\text { Unicentric trial, } \\
\text { single-arm, pilot study }\end{array}$ & 44 & $\begin{array}{l}\text { Topical } 10 \% \\
\text { Amitriptyline } \\
\text { cream bid }\end{array}$ & $\begin{array}{c}\text { CIPN with } \\
\text { NCI-CTCAE } \\
\text { v4.0 grade >1 }\end{array}$ & $\begin{array}{c}\text { Haematological } \\
\text { or solid tumours. } \\
\text { Previous } \\
\text { treatment with } \\
\text { neurotoxic ChT }\end{array}$ & $\begin{array}{l}\text { VAS on the } \\
\text { baseline; and } \\
\text { at } 1,2 \text { and } 4 \\
\text { weeks; and } \\
\text { then monthly } \\
\text { up to } 1 \text { year }\end{array}$ & $\begin{array}{l}\text { Median VAS } \\
\text { score decreased } \\
\text { from } 7(4-9) \\
\text { to } 2(0-4) \\
\text { after } 4 \text {-week } \\
\text { treatment }\end{array}$ & $\begin{array}{l}\text { Discontinuation } \\
\text { is only } 1 \text { patient } \\
\text { (skin irritation) }\end{array}$ & 11 & $\begin{array}{c}2,3,4,5 \\
6,9,13 \\
16,17 \\
18,19\end{array}$ \\
\hline $\begin{array}{c}\text { Prinsloo S. } \\
(2017, \text { USA) } \\
{[22]}\end{array}$ & $\begin{array}{c}\text { Unicentric, } \\
\text { randomized, } \\
\text { waitlist-controlled trial, } \\
\text { pilot study }\end{array}$ & 62 & $\begin{array}{c}\text { Neurofeedback: } \\
20 \text { sessions } \\
\text { (twice a week) }\end{array}$ & $\begin{array}{c}\text { CIPN with } \\
\text { NCI-CTCAE } \\
\text { v4.0 grade } \\
\geq 3 \text { and/or } \\
\text { neuropathic } \\
\text { pain (NRS } \geq 4 \text { ), } \\
\text { for } \geq 3 \text { months } \\
\text { beyond ChT } \\
\text { completion }\end{array}$ & $\begin{array}{l}\text { Any cancer and } \\
\text { stage. Previous } \\
\text { treatment with } \\
\text { neurotoxic } \\
\text { ChT }\end{array}$ & $\begin{array}{l}\text { BPI-SF } \\
\text { worst-pain } \\
\text { item, on the } \\
\text { baseline and } \\
\text { then weekly } \\
\text { until the end }\end{array}$ & $\begin{array}{l}\text { Decrease in } \\
\text { BPI-SF worst } \\
\text { pain (mean } \\
\text { change score: } \\
-2.43 \text { vs. } 0,09, \\
p=0.001 \text { ) }\end{array}$ & $\begin{array}{l}\text { All pts completed } \\
\text { NFB treatment, } \\
\text { without } \\
\text { discontinuation } \\
\text { problem or } \\
\text { side effects }\end{array}$ & 13 & $\begin{array}{c}1,2,3,4 \\
5,7,9 \\
12,13 \\
16,17 \\
18,19\end{array}$ \\
\hline
\end{tabular}

Legends: N: size sample; ChT: chemotherapy; CIPN: Chemotherapy-induced peripheral neuropathy; NCCI-CTCAE: National Cancer Institute's Common Toxicity Criteria for Adverse Events; VAS: Visual Analogue Scale; pts: patients; BPI-SF: Brief Pain Inventory-Short Form; NRS: Numeric Rating Scale; tid: three times a day; bid: twice a day; ENS: Eastern Cooperative Oncology Group neuropathy scale; EORTC QLQ-CIPN20: European Organization for Research and Treatment of Cancer Quality of Life Questionnaire CIPN20.

The largest sample size belongs to Gewandter et al. with a total of 462 patients [28] and the smallest study included 18 patients [23]. Of 11 selected studies, 7 were randomised trials [20] [21] [22] [25] [27] [28] [29], which 5 were placebo-controlled [20] [25] [27] [28] [29] and 3 had a crossover designer trial [20] [21] [25]. Four were multicentric trials [20] [25] [27] [28]. Most studies failed to distinguish the acute and chronic forms CIPN. Chronic CIPN was defined in only 4 trials [20] [22] [25] [27], as the beginning of the symptoms at least 1 or more months. Although CIPN was not defined, in 1 study, patients who had completed chemotherapy at least 1 month were included [28]. 


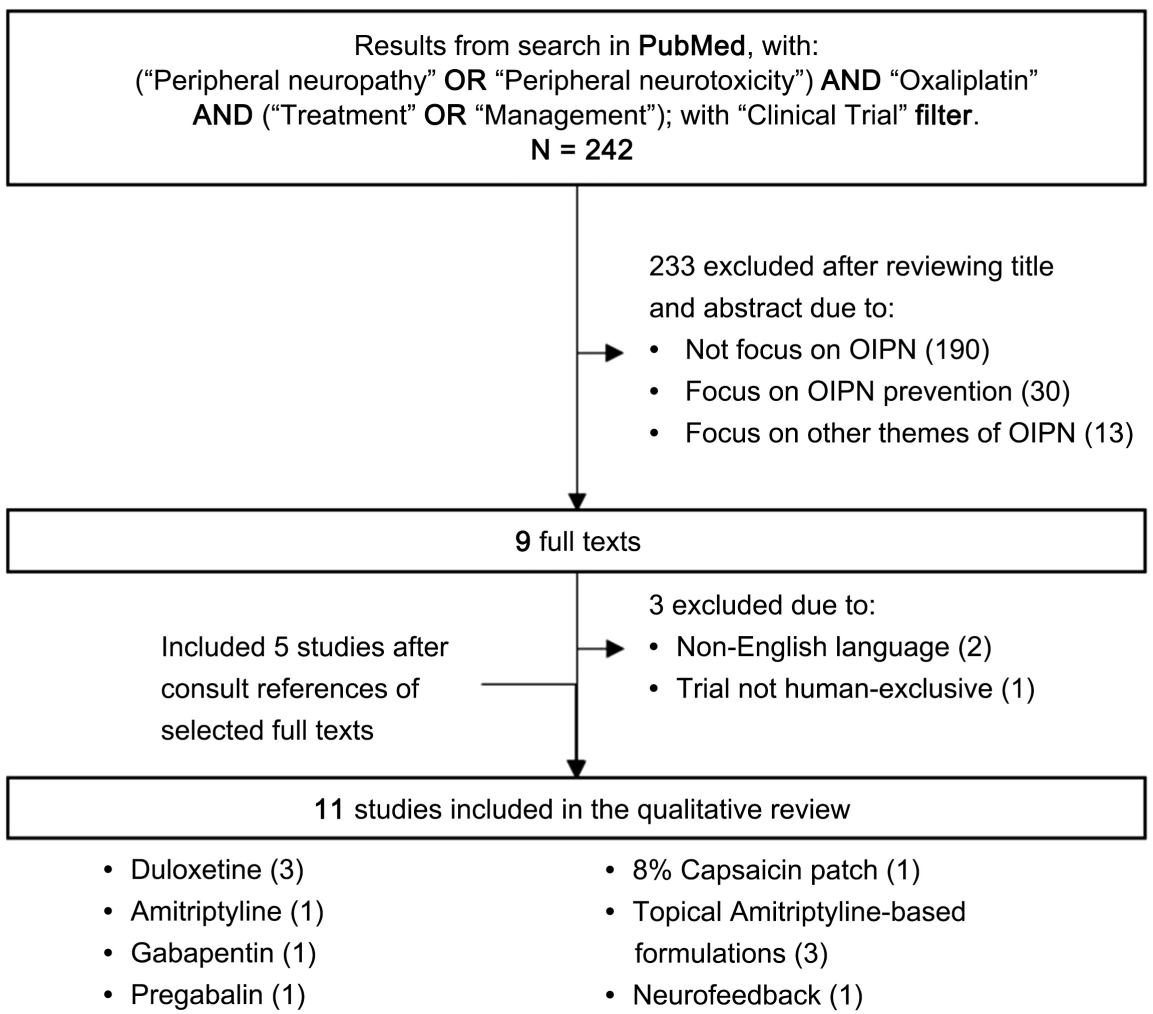

Figure 1. Flow diagram of papers accepted and reject during selection process.

Only 3 studies included patients treated with exclusively oxaliplatin-based chemotherapy [19] [23] [26]. Of these, 1 study did not specify the oxaliplatin-based ChT regimen [23]. The cumulative dose was described in 2 studies [19] [23]. The sample size of patients submitted to oxaliplatin-based ChT ranged from 4 [22] to 129 [20].

Across the 11 studies reviewed here, there was a large variation in the methods used to assess peripheral neuropathy, in terms of the criteria employed and efficacy measures. National Cancer Institute's Common Toxicity Criteria for Adverse Events (NCI-CTCAE) was the most neuropathy assessment criteria used [19] [20] [22] [24] [26]. The most common primary efficacy measures used to evaluate neuropathic pain were visual analogue scale (VAS) [19] [21] [24] and numeric rating scale (NRS) [20] [23] [25]. Other CIPN symptoms (like numbness, burning, tingling and electric shock sensation) were more frequently graded using NCI-CTCAE [19] [24] [26].

A total number of quality criteria, by study, ranged from 10 to 16 points (table 2 ). Of these, only one study was high quality (defined by a total criteria number of $>15$ ) [20].

\section{Discussion}

\subsection{Discussion by Treatment Strategies}

\subsubsection{Duloxetine}

Duloxetine is an antidepressant, a selective serotonin and norepinephrine reup- 
take inhibitor (SNRI), with proven effectiveness in the treatment of diabetic neuropathic pain. The efficacy on OIPN and safety of this drug were proved by 3 trials [19] [20] [21].

The first study was an open-label trial, with a single-arm, which enrolled 39 Chinese patients with chronic neuropathy and colon cancer in stage III and IV, after treatment with oxaliplatin-based ChT [19]. Concomitant antidepressants or anticonvulsants weren't permitted. After 12 weeks of treatment with duloxetine $(60 \mathrm{mg} /$ day, orally), there was a significant reduction in neurotoxicity: $63 \%$ of patients have a VAS score decreased by more than $30 \%$ at the end of the 12 weeks, and $47 \%$ of patients have an NCI-CTCAE v3.0 grade improvement (a lower grade at the end of treatment compared to the grade at the beginning, which mean impairment of daily function). The major limitations of this study were the little size sample and the absence of a controlled arm.

The benefit of duloxetine $(60 \mathrm{mg} /$ day) for treating chronic CIPN was confirmed by a multicentric, randomised, placebo-controlled crossover trial, in 2013 [20]. This study enrolled 231 patients with any cancer diagnosis and any stage, who received taxane or platinum-based ChT (129 patients were undergoing to oxaliplatin). After the initial 5 weeks of treatment, cross-over occurred following a 2-weeks wash-out period for a total study duration of 14 weeks. Chronic CIPN was defined by the presence of the symptoms for $\geq 3$ months beyond ChT completion [20]. Five weeks of duloxetine treatment resulted in a statistically and clinically significant improvement in pain, as like as, it improved function and quality of life. In the analysis by subgroup, it was also found that the effectiveness of the treatment was greater in the group that had previously undergone oxaliplatin-based ChT, rather than taxane-induced painful neuropathy. In this review, this is the unique phase III trial that elucidates an effective intervention in the control of neuropathic pain secondary to OIPN.

The effectiveness of duloxetine was also supported by a small, randomised Japanese trial, employing 34 patients, comparing duloxetine to vitamin [21]. The patients were divided into 2 groups with equivalent clinical and demographic characteristics in both arms. After the initial 4 weeks, cross-over occurred following 2 to 4 weeks of wash-out period. After 4 weeks of treatment, in the 2 arms, duloxetine was shown to be more effective than vitamin B12. Unlike previous studies, the dose of duloxetine used was $40 \mathrm{mg}$ /day (a dose regulated in Japan). Although the use of vitamin B12 (1.5 mg/day, orally) is a Japanese daily practice, no phase II or III study proves the effectiveness of vitamin B12 in this context. The sample of this study was very heterogeneous, including patients with different oncological diseases, submitted to different ChT regimens. Only 5 patients were undergoing to oxaliplatin-based ChT; consequently, this trial didn't prove the benefit of duloxetine on the treatment of OIPN. Besides, patients previously medicated with opioids and gabapentinoids were allowed to enter this study, and it is not possible to exclude a synergistic effect from the current therapy. 
Unfortunately, the magnitude of benefit of duloxetine is modest and much less than is desirable. Relatively to safety, the discontinuation rate was significant and ranged from $11 \%$ to $23.1 \%$. The adverse effects more frequent were fatigue (7\% - 18\%), nausea (5\% - 10\%), insomnia (5\%) and somnolence (5\%). Most of the adverse effects were manageable. It should be noted that the discontinuation occurred only in the first 3 weeks of treatment with duloxetine at $60 \mathrm{mg} / \mathrm{day}$ [19]. It means that if the patients can tolerate the duloxetine dosages at the beginning of treatment, they can be expected to maintain duloxetine without discontinuation.

\subsubsection{Amitriptyline}

Amitriptyline was also tested in the same setting of patients. Arandomized, double-blind, placebo-controlled trial enrolled to 44 patients with CIPN (numbness, tingling, pain) with a severity of $\geq 3 / 10$ [29]. Patients, who reported neuropathic symptoms and were submitted at least 2 months of neurotoxic ChT, were included. In this trial, amitriptyline was started at $10 \mathrm{mg} / \mathrm{day}$, oral, and if tolerated, the dose was escalated ( $10 \mathrm{mg}$ per week) to a maximum of $50 \mathrm{mg} /$ day, followed by a stable dose $\geq 4$ weeks. The primary endpoint was relief of neuropathic symptoms, measured with numeric scales of 0 - 10 for each symptom (like NRS for pain) and reported two times per week in diaries during 8 weeks. The study was prematurely terminated due to poor recruitment. Only 33 patients were included in the final analysis (17 on amitriptyline group). Results from this study showed no significant effect of low-dose amitriptyline on neuropathic symptoms (mean global improvement of $3.4 \pm 3.6$ in the amitriptyline group and $1.9 \pm 3.1$ in the placebo group). However, there was a trend toward global improvement (using a five-point verbal rating scale) and improved quality of life (assessed by EORTC QLQ-C30 questionnaire; $p=0.038$ ) in favour of the amitriptyline arm. This results probably due to low dose of the amitriptyline and small sample size. Amitriptyline was well tolerated on the target dose. Only 14 patients were submitted to platinum agents; but the number of patients submitted to oxaliplatin was not mentioned, so the amitriptyline isn't an effective treatment of OIPN.

\subsubsection{Gabapentin}

Gabapentin is an antiepileptic, GABA analogue, which is effective in treating symptoms from several neuropathic syndromes. However, a phase 3 randomised, double-blind, placebo-controlled, crossover trial failed to prove the efficacy of gabapentin in the treatment of CIPN [25]. In this trial included 115 patients with symptomatic CIPN for $\geq 1$ month and pain scores of NRS $\geq 4$ or Eastern Cooperative Oncology Group (ENS) sensory neuropathy $\geq 1$, who were randomly assigned gabapentin (target dose $=900 \mathrm{mg}$ tid) or placebo. After the initial six weeks, cross-over occurred following a 2-week washout period. Changes in symptom severity, measured by NRS and ENS, were similar in both groups. Adverse events were mild and similar in both groups. So, the study was not able to confirm the benefit of the use of gabapentin in ameliorating peripheral neu- 
ropathy. Besides that, this study included ChT regimens with other neurotoxic chemo agents (taxanes, platinum agents, etc.). Only $<23$ patients were submitted to oxaliplatin, and there weren't reported outcomes in this subgroup.

\subsubsection{Pregabalin}

Pregabalin is a GABA analogue, structurally related to gabapentin, but it has rapid dose-independent absorption and a more tolerable side effect profile. Pregabalin achieved moderate efficacy in a non-randomised trial, which included 23 patients with gastrointestinal cancer undergoing oxaliplatin-based ChT [26]. In this trial, pregabalin was started at $50 \mathrm{mg}$, oral, three times a day (tid), and if tolerated, the dose was escalated to a maximum of $150 \mathrm{mg}$ tid. In the majority of patients (48\%), neuropathy improved by 1 to 2 grades (NCI-CTCAE v3.0), with the onset of benefit observed in 2 - 6 weeks. The best benefit was observed at a dose of $150 \mathrm{mg}$ tid, but patients experience significant symptomatic relief even at lower doses of $50 \mathrm{mg}$ tid. The intensity pain reduction with pregabalin wasn't reported. So, the efficacy measure used does not allow direct comparison with other studies. Besides, although the $\mathrm{ChT}$ regimens were described, the cumulative dose of oxaliplatin wasn't reported. The chronicity of the symptoms is not explicit in this study.

\subsubsection{High-Dose $8 \%$ Capsaicin Patch}

Based on its effectiveness on the treatment of neuropathic pain in HIV-associated neuropathy and post-herpetic neuralgia, high-dose topical capsaicin was tested on the treatment of CIPN-associated pain. A single-centre trial, the application of high-dose capsaicin patch resulted in significant pain relief, without considerable adverse events [23]. In a sample of 18 colon cancer patients undergoing oxaliplatin-based chemotherapy, with painful peripheral polyneuropathy, there was an average pain score in approximately $84 \%$ to $97 \%$ patients after 12 weeks of application of capsaicin patch. There was a reduction in pain intensity from $7.45 \pm 1.14$ to $0.20 \pm 0.41$ (after 12 weeks), using NRS. It is not clearly described how many patients experienced pain relief. Patients with lower sensitivity to neurotoxic agents (patients whom the symptoms appeared after the treatment with higher cumulative doses of oxaliplatin: $\geq 648.07 \mathrm{mg} / \mathrm{m}^{2}$ ) have a better response to treatment and pain reduction. About $50 \%$ of patients were being treated with gabapentinoids and/or antidepressants. We do not know in what context these drugs were prescribed and what effect this has on neuropathic pain previously. Although the symptoms were described, the chronicity of these wasn't explicit in this study, neither the oxaliplatin-based ChT regimens. A small sample is the major limitation of this study.

\subsubsection{Topical Amitriptyline}

The effects of topical amitriptyline in the treatment of CIPN have been evaluated in 3 trials: 2 randomized, double-blind, placebo-controlled trials and 1 clinical trial with a single arm. The first 2 trials assessed topical amitriptyline adminis- 
tered in low concentrations $(<5 \%)$, in two different formulations combined with other topical analgesic agents (baclofen and ketamine) [27] [28]. The third trial assessed topical amitriptyline in high concentrations (10\%) [24]. These 3 preparations can only be manufactured by a compounding pharmacy.

Barton et al. evaluated the efficacy and safety of topical treatment with a compounded pluronic lecithin organogel containing $10 \mathrm{mg}$ of baclofen, $40 \mathrm{mg}$ of amitriptyline, and $20 \mathrm{mg}$ of ketamine (BAK gel) in each $1.31 \mathrm{~g}$ measured dose [27]. This study (NCCTG trial N06CA) included 208 patients with CIPN (mostly after treatment with taxanes and oxaliplatin), who applied the BAK gel to at most four areas of pain, numbness, and/or tingling at a single time, around one level spoonful of gel on each area, twice daily, for 4 weeks. The primary endpoint was the baseline-adjusted sensory subscale of the European Organization for Research and Treatment of Cancer Quality of Life Questionnaire CIPN20 (EORTC QLQ-CIPN20), at 4 weeks. There was a trend in favour of the active arm, with a mean \pm standard deviation (SD) change from baseline at 4 weeks of $8.1 \pm 15.1$ for the BAK arm versus $3.8 \pm 15.5$ for the placebo arm $(p=0.053)$. Additionally, Brief Pain Inventory wasn't significantly different between the 2 arms. The greatest improvements were related to the symptoms of tingling, cramping, and shooting/burning pain in the hands and difficulty in holding a pen. There were no reported toxicities associated with the topical combination and no evidence of systemic toxicity. Unfortunately, given the efficacy measure used, it is not possible to compare with other studies. Besides, at baseline, $64 \mathrm{pa}-$ tients were a previous exposure to oxaliplatin and 25 were undergoing to oxaliplatin-based ChT, and there weren't reported outcomes in this subgroup.

Other study tested other topical treatment $-2 \%$ ketamine plus $4 \%$ amitriptyline cream (KA cream), on 462 cancer survivors with CIPN [28]. The patients applied $4 \mathrm{~g}$ of cream (using a measuring device), twice daily, during 6 weeks, to each area with pain, numbness, and/or tingling at a single time. They completed a seven-day daily pain, numbness and tingling diary one week before study entry, and at 3 and 6 weeks after enrolment. The average score at 6 weeks was the primary outcome. This study was negative because the KA cream application wasn't associated with a decrease in CIPN symptoms $(p=0.363)$. Secondary analyses assessing pain alone, using NRS score, also showed no benefit for KA cream $(p=0.400)$. Despite gastrointestinal tumours being the second most common neoplasm (27\%), the number of patients submitted to oxaliplatin was not mentioned.

Finally, a pilot study tested the high concentration amitriptyline cream in the treatment of patients with newly diagnosed CIPN for less than 1 month (group 1) or CIPN for more than 1 month who had not to respond to previous pharmacologic treatment (antidepressants, anticonvulsants, opioids) and discontinue this previous treatment (group 2) [24]. Eligible patients were asked to apply a thin layer of $1 \mathrm{~g}$ of $10 \%$ amitriptyline cream, and gently rub it in, twice a day to the affected areas. They should leave the cream on for 30 minutes before hand 
washing without need for foot-washing. Topical treatment should be maintained during the whole ChT course and up to 1 year. This study included a small and very heterogeneous sample: 39patients had haematological cancer and 5 had solid tumours, all submitting to different neurotoxic ChT (taxanes, platinum agents, bortezomib). Only 14 patients (32\%) underwent oxaliplatin-based ChT. After 1 week of treatment, there was a decrease of least 3 points in the VAS in all patients. And after 4 weeks, median VAS pain score was significantly reduced from 7 at baseline to $2(p<0.0001)$. No difference was seen between group 1 and 2. However, we don't know what percentage of patients had a reduction of VAS greater than $30 \%$, to compare with previous studies with duloxetine. Even so, in this study, 3 positive aspects were highlighted. First, 9 patients (20\%) stopped amitriptyline after 1 month of treatment because of total relief of pain (VAS 0-1) and experienced no recrudescence in CIPN symptoms, that suggesting a long-lasting post-therapy effect. Second, only 1 patient discounted the topical treatment due to skin irritability and this patient had a previous skin disorder; so this treatment appears safety. And finally, reduced initial ChT doses in 11 patients, as well as, ChT discontinued in 5 patients were resumed after 1 month of topical amitriptyline application which provided efficient pain control (reduction of VAS pain score to a range of 0 to 3 ). Large and randomised studies are needed to confirm these 3 topics.

\subsubsection{Neurofeedback}

A pilot study examined whether electroencephalogram (EEG) neurofeedback (NFB) could alleviate CIPN symptoms [22]. This non-pharmacological treatment was a neuromodulatory intervention which can teach participants to interpret pain signals differently by affecting changes in brain regions that are active during pain conditions. In this randomized study, patients who had CIPN at least 3 months after completion of $\mathrm{ChT}$ were included. They were randomised in two groups: NFB group (30) or a wait-list control (WLC) group (32). The NFB group underwent 20 sessions of NFB, twice a week, over a maximum of 10 weeks. In each session, the participants watched and responded to their own EEGs while playing a game for 45 minutes per session; when they maintained their EEG waveform amplitude over a chosen threshold and inhibited less desirable waveforms, they were given rewarding feedback with a picture and a beep; the game paused when the participant did not match the thresholds preprogramed into the software, and no auditory or visual feedback was given. The primary endpoint was the change in worst pain related to CIPN, assessed by Brief Pain Inventory short form (BPI-SF) worst-pain item, from the baseline to the end of the treatment period (10 weeks). The results showed that NFB was an effective treatment, because there was a significant improvement on the BPI-SF worst-pain item on the NFB group (mean change score -2.43 vs. 0.09 on the WLC group, $p=0.001$ ). There were also improvements in other neuropathic symptoms like numbness and tingling. All patients submitted to NFB completed it, without any negative side effects. However, in this study, only 4 patients un- 
derwent to oxaliplatin-based ChT, and the efficacy of this technique wasn't analyzed in this subgroup. Limitations of this study were the significant predominance of female participants (mostly had breast cancer and were treated with taxanes), as well as, the absence of placebo group.

\subsection{Limitations}

Principal review-level limitations include the exclusion of possible relevant studies not published in English and the exclusion of retrospective works and clinical case series. Besides that, the authors admit possible selection bias, since only one literature database was used, and a search filter was used. Thus, it is assumed that there may be relevant tests that were not automatically included.

Other limitations are dependent of each trial and concern about study design, sample size and CIPN assessment. Most studies were unicentric and single-arm, with a little sample and medium quality. Direct comparative outcomes were prohibited by the variety of methods on participation selection, neuropathy assessment criteria and on efficacy assessment measure. Additionally, most of the studies used a clinician-based assessment. This type of evaluation can compromise the recognition of the true symptomatic burden of neurotoxicity and functional consequences. Consequently, it can also compromise the assessment of treatment effectiveness.

\section{Conclusion}

Unfortunately, in the last decade, there wasn't an improvement in the treatment of oxaliplatin-induced neuropathy. Until now, the duloxetine is the unique drug with moderate effects on the treatment based on a multicentric, randomised, double-blind, placebo-controlled crossover trial with significant sample size. There is insufficient evidence to support a recommendation for any other treatment. Larger placebo-controlled trials to validate the effectiveness and safety of the other treatment strategies are warranted in patients treated with oxaliplatin.

\section{Author Contributions}

All authors contributed to this article. The first draft of the manuscript was written by Alda Tavares. Ana Agreloand Manuela Machado commented on previous versions of the manuscript.

\section{Conflicts of Interest}

The authors declare no conflicts of interest regarding the publication of this paper.

\section{References}

[1] Capdevila, J., Elez, E., Peralta, S., Macarulla, T., Ramos, F.J. and Tabernero, J. (2008) Oxaliplatin-Based Chemotherapy in the Management of Colorectal Cancer. Expert Review of Anticancer Therapy, 8, 1223-1236.

https://doi.org/10.1586/14737140.8.8.1223 
[2] Argyriou, A.A., Polychronopoulos, P., Iconomou, G., Chroni, E. and Kalofonos, H.P. (2008) A Review on Oxaliplatin-Induced Peripheral Nerve Damage. Cancer Treatment Reviews, 34, 368-377. https://doi.org/10.1016/j.ctrv.2008.01.003

[3] Sereno, M., et al. (2014) Oxaliplatin Induced-Neuropathy in Digestive Tumors. Critical Reviews in Oncology/ Hematology, 89, 166-178. https://doi.org/10.1016/j.critrevonc.2013.08.009

[4] Saif, M.W. and Reardon, J. (2005) Management of Oxaliplatin-Induced Peripheral Neuropathy. Therapeutics and Clinical Risk Management, 1, 249-258.

[5] Cersosimo, R.J. (2005) Oxaliplatin-Associated Neuropathy: A Review. Annals of Pharmacotherapy, 39, 128-135. https://doi.org/10.1345/aph.1E319

[6] Pasetto, L.M., D’Andrea, M.R., Rossi, E. and Monfardini, S. (2006) Oxaliplatin-Related Neurotoxicity: How and Why? Critical Reviews in Oncology/ Hematology, 59, 159-168. https://doi.org/10.1016/j.critrevonc.2006.01.001

[7] Bennett, B.K., Park, S.B., Lin, C.S., Friedlander, M.L., Kiernan, M.C. and Goldstein, D. (2012) Impact of Oxaliplatin-Induced Neuropathy: A Patient Perspective. Support Care Cancer, 20, 2959-2967. https://doi.org/10.1007/s00520-012-1428-5

[8] Beijers, A.J., Mols, F. and Vreugdenhil, G. (2014) A Systematic Review on Chronic Oxaliplatin-Induced Peripheral Neuropathy and the Relation with Oxaliplatin Administration. Support Care Cancer, 22, 1999-2007. https://doi.org/10.1007/s00520-014-2242-z

[9] Mols, F., Beijers, T., Vreugdenhil, G. and van de Poll-Franse, L. (2014) Chemotherapy-Induced Peripheral Neuropathy and Its Association with Quality of Life: A Systematic Review. Support Care Cancer, 22, 2261-2269. https://doi.org/10.1007/s00520-014-2255-7

[10] Pulvers, J.N. and Marx, G. (2017) Factors Associated with the Development and Severity of Oxaliplatin-Induced Peripheral Neuropathy: A Systematic Review. Asia-Pacific Journal of Clinical Oncology, 13, 345-355. https://doi.org/10.1111/ajco.12694

[11] Derksen, T.M., Bours, M.J., Mols, F. and Weijenberg, M.P. (2017) Lifestyle-Related Factors in the Self-Management of Chemotherapy-Induced Peripheral Neuropathy in Colorectal Cancer: A Systematic Review. Evidence-Based Complementary and Alternative Medicine, 2017, Article ID: 7916031. https://doi.org/10.1155/2017/7916031

[12] Jordan, B., Jahn, F., Beckmann, J., Unverzagt, S., Müller-Tidow, C. and Jordan, K. (2016) Calcium and Magnesium Infusions for the Prevention of Oxaliplatin-Induced Peripheral Neurotoxicity: A Systematic Review. Oncology, 90, 299-306. https://doi.org/10.1159/000445977

[13] Argyriou, A.A. (2015) Updates on Oxaliplatin-Induced Peripheral Neurotoxicity (OXAIPN). Toxics, 3, 187-197. https://doi.org/10.3390/toxics3020187

[14] Zajączkowska, R., Kocot-Kępska, M., Leppert, W., Wrzosek, A., Mika, J. and Wordliczek, J. (2019) Mechanisms of Chemotherapy-Induced Peripheral Neuropathy. International Journal of Molecular Sciences, 20, 1451. https://doi.org/10.3390/ijms20061451

[15] Starobova, H. and Vetter, I. (2017) Pathophysiology of Chemotherapy-Induced Peripheral Neuropathy. Frontiers in Molecular Neuroscience, 10, 174. https://doi.org/10.3389/fnmol.2017.00174

[16] Hershman, D.L., et al. (2014) Prevention and Management of Chemotherapy-Induced Peripheral Neuropathy in Survivors of Adult Cancers: American Society of Clinical Oncology Clinical Practice Guideline. Journal of Clinical Oncology, 
32, 1941-1967.

[17] Moher, D., Liberati, A., Tetzlaff, J., Altman, D.G. and Group, P. (2009) Preferred Reporting Items for Systematic Reviews and Meta-Analyses: The PRISMA Statement. Journal of Clinical Epidemiology, 62, 1006-1012.

https://doi.org/10.1016/j.jclinepi.2009.06.005

[18] Schulz, K.F., Altman, D.G. and Moher, D. (2010) CONSORT 2010 Statement: Updated Guidelines for Reporting Parallel Group Randomised Trials. Journal of Pharmacology \& Pharmacotherapeutics, 1, 100-107. https://doi.org/10.4103/0976-500X.72352

[19] Yang, Y.H., et al. (2012) Duloxetine Improves Oxaliplatin-Induced Neuropathy in Patients with Colorectal Cancer: An Open-Label Pilot Study. Support Care Cancer, 20, 1491-1497. https://doi.org/10.1007/s00520-011-1237-2

[20] Smith, E.M., et al. (2013) Effect of Duloxetine on Pain, Function, and Quality of Life among Patients with Chemotherapy-Induced Painful Peripheral Neuropathy: A Randomized Clinical Trial. JAMA, 309, 1359-1367.

[21] Hirayama, Y., et al. (2015) Effect of Duloxetine in Japanese Patients with Chemotherapy-Induced Peripheral Neuropathy: A Pilot Randomized Trial. International Journal of Clinical Oncology, 20, 866-871.

https://doi.org/10.1007/s10147-015-0810-y

[22] Prinsloo, S., et al. (2017) Randomized Controlled Trial of Neurofeedback on Chemotherapy-Induced Peripheral Neuropathy: A Pilot Study. Cancer, 123, 1989-1997. https://doi.org/10.1002/cncr.30649

[23] Filipczak-Bryniarska, I., et al. (2017) High-Dose 8\% Capsaicin Patch in Treatment of Chemotherapy-Induced Peripheral Neuropathy: Single-Center Experience. Medical Oncology, 34, 162. https://doi.org/10.1007/s12032-017-1015-1

[24] Rossignol, J., et al. (2019) High Concentration of Topical Amitriptyline for Treating Chemotherapy-Induced Neuropathies. Support Care Cancer, 27, 3053-3059. https://doi.org/10.1007/s00520-018-4618-y

[25] Rao, R.D., et al. (2007) Efficacy of Gabapentin in the Management of Chemotherapy-Induced Peripheral Neuropathy: A Phase 3 Randomized, Double-Blind, Placebo-Controlled, Crossover Trial (N00C3). Cancer, 110, 2110-2118. https://doi.org/10.1002/cncr.23008

[26] Saif, M.W., Syrigos, K., Kaley, K. and Isufi, I. (2010) Role of Pregabalin in Treatment of Oxaliplatin-Induced Sensory Neuropathy. Anticancer Research, 30, 2927-2933.

[27] Barton, D.L., et al. (2011) A Double-Blind, Placebo-Controlled Trial of a Topical Treatment for Chemotherapy-Induced Peripheral Neuropathy: NCCTG Trial N06CA. Support Care Cancer, 19, 833-841. https://doi.org/10.1007/s00520-010-0911-0

[28] Gewandter, J.S., et al. (2014) A Phase III Randomized, Placebo-Controlled Study of Topical Amitriptyline and Ketamine for Chemotherapy-Induced Peripheral Neuropathy (CIPN): A University of Rochester CCOP Study of 462 Cancer Survivors. Support Care Cancer, 22, 1807-1814. https://doi.org/10.1007/s00520-014-2158-7

[29] Kautio, A.L., Haanpää, M., Saarto, T. and Kalso, E. (2008) Amitriptyline in the Treatment of Chemotherapy-Induced Neuropathic Symptoms. Journal of Pain and Symptom Management, 35, 31-39.

https://doi.org/10.1016/j.jpainsymman.2007.02.043 


\section{Abbreviations}

BAK: baclofen, amitriptyline and ketamine;

bid: twice a day;

BPI-SF: Brief Pain Inventory-Short Form;

ChT: Chemotherapy;

CIPN: Chemotherapy-induced peripheral neuropathy;

EEG: electroencephalogram;

ENS: Eastern Cooperative Oncology Group neuropathy scale;

EORTC QLQ-CIPN20: European Organization for Research and Treatment of Cancer Quality of Life Questionnaire CIPN20;

EORTC QLQ-C30: European Organization for Research and Treatment of Cancer Quality of Life Questionnaire C30;

KA: ketamine and amitriptyline;

MeSH: medical subject heading;

NCCI-CTCAE: National Cancer Institute's Common Toxicity Criteria for Adverse Events;

NFB: Neurofeedback;

NRS: Numeric Rating Scale;

OIPN: Oxaliplatin-induced peripheral neuropathy;

PRISMA: Preferred Reporting Items for Systematic Reviews and Meta-Analysis;

SD: standard deviation;

SNRI: serotonin and norepinephrine reuptake inhibitor;

tid: three times a day;

VAS: Visual Analogue Scale;

WLC: wait-list control. 